\title{
Perfil eletroforético das proteínas de fase aguda em caprinos experimentalmente infectados com Trypanosoma evansi
}

Thais Helena Constantino PATELLI ${ }^{1}$

Luiz Carlos MARQUES ${ }^{1}$

José Jurandir FAGLIARI ${ }^{1}$

Paulo César SILVA ${ }^{1}$

\section{Correspondência para:}

Rua São Paulo, 2812, 86.360-000

Bandeirantes-PR, tpatelli@hotmail.com

Recebido para publicação: 11/09/2006 Aprovado para publicação: 28/08/2008

\author{
1 - Departamento de Clínica e Cirurgia Veterinária da Faculdade de Ciências \\ Agrárias e Veterinárias da Universidade Estadual Paulista "Julio de Mesquita Filho", \\ Jaboticabal-SP
}

Resumo

Palavras-chaves: Eletroforese.

Considerado como um dos principais agentes das tripanossomíases, Trypanosoma evansi causa uma doença genericamente conhecida como Proteínas. Cabras. "surra" e de ampla distribuição geográfica. Esse trabalho teve como objetivo principal estudar o perfil eletroforético das proteínas de fase aguda de caprinos experimentalmente infectados com este hematozoário. Para tal, foram utilizadas dez fêmeas caprinas, com vários graus de mestiçagem, com idade aproximada de 4 meses, clinicamente sadias e sorologicamente negativas para a presença de anticorpos anti-T. evansi (Reação de Imunofluorescência Indireta RIFI). Os animais foram divididos em dois grupos: grupo 1 (G1): seis animais inoculados via intravenosa com 2,38 x $10^{6}$ tripomastigotas de T. evansi e grupo 2 (G2): quatro animais utilizados como testemunhos. O sangue para a obtenção do soro foi obtido diariamente até o $14^{\circ}$ dia após a inoculação (DAI), semanalmente até o $98^{\circ} \mathrm{DAI}$ e quinzenalmente até o $364^{\circ} \mathrm{DAI}$. O fracionamento das proteínas foi obtido por em gel de poliacrilamida contendo duodecil sulfato de sódio (SDS- PAGE). Vinte e uma proteínas foram encontradas nos soros caprinos. Destas, oito foram nominalmente identificadas; fosforilase, transferrina, albumina, antitripsina, glicoproteína ácida, haptoglobina, hemoglobina e imunoglobulina de cadeia leve.

\section{Introdução}

Dentre as principais tripanossomíases, a "surra", como é conhecida genericamente tem como agente causador o Tripanossoma. evansi. Este protozoário, pertencente ao gênero Trypanosoma, subgênero Trypanozoon, afeta grande número de animais. ${ }^{1}$ Apesar da distribuição cosmopolita, as tripanossomíases animais apresentam maior ocorrência nos países tropicais e sub-tropicais principalmente na África, Ásia e Américas. ${ }^{2}$

Os principais hospedeiros acometidos variam geograficamente, entretanto, os búfalos, bovinos, camelos e eqüídeos são particularmente sensíveis. ${ }^{3}$

O período pré-patente tem duração de aproximadamente duas semanas. Em caprinos,
Ngeranwa et al. ${ }^{4}$ observaram período prépatente que variou de 2 a 4 dias e Sharma et al. ${ }^{5} \mathrm{em}$ condições experimentais, detectaram parasitemias nos caprinos cerca de sete dias após a inoculação.

O diagnóstico dessa enfermidade tornase relativamente simples em animais com infecções agudas, quando os parasitas estão presentes em grande número no sangue periférico. A detecção direta do parasita é comumente realizada por técnicas como o exame da gota espessa, o método de concentração (centrifugação) de Strout e contagem de parasitas em esfregaços sangüíneos. ${ }^{6}$ Em adição aos métodos de diagnóstico, o proteinograma, pode auxiliar no diagnóstico das tripanossomíases. ${ }^{7}$

As proteínas de fase aguda são grupos 
de glicoproteínas produzidos principalmente pelo fígado, sendo suas produções estimuladas por citocinas específicas, liberadas por leucócitos e macrófagos, com rápidas elevações de sua concentração no plasma durante condições inflamatórias. ${ }^{8}$ Essas proteínas podem ser classificadas em positivas, representadas pela ceruloplasmina, fibrinogênio, proteína C-reativa, antitripsina e haptoglobina e em negativas, como a préalbumina, a albumina e a transferrina. ${ }^{9}$

$\mathrm{Na}$ clínica, os métodos de detecção de proteínas de fase aguda têm auxiliado o diagnóstico de processos inflamatórios. Alguns trabalhos comparativos sugerem que as proteínas de fase aguda são mais sensíveis para detecção da inflamação do que a análise hematológica. ${ }^{10}$ Em ovinos, Skinner e Roberts ${ }^{11}$ demonstraram que a haptoglobina foi melhor indicador de infecção bacteriana do que os exames hematológicos.

Alterações em diferentes frações protéicas do soro foram observadas em camelos $^{12}$, bezerros ${ }^{13}$ e em eqüinos ${ }^{14}$ infectados com T. evansi. Em um cão infectado com este hematozoário, Sandoval et $a .^{15}$ encontraram variações nos teores séricos das proteínas totais e na albumina e oscilações nos teores séricos da transferrina, haptoglobina e albumina foram obtidos por Passos $^{16}$ em ovinos experimentalmente infectados. Em ratos Wistar experimentalmente infectados com T. evansi, Teixeira ${ }^{6}$ identificou nominalmente 12 proteínas de fase aguda, com variados graus de oscilações durante o período observado.

O presente trabalho é plenamente justificável devido à relevância da tripanossomíase, especialmente nos países tropicais, aliado a escassez de literatura na espécie caprina. Sendo assim, o objetivo deste estudo foi avaliar o proteinograma de caprinos infectados experimentalmente com T. evansi.

\section{Material e Método}

Para este experimento foram utilizadas dez fêmeas caprinas, com vários graus de mestiçagem, com aproximadamente
4 meses de idade e clinicamente sadias. Os animais foram mantidos em baias devidamente teladas, junto ao setor de grandes animais do Laboratórios de Pesquisas do Departamento de Clinica e Cirurgia Veterinária da FCAV/Unesp. Durante toda fase experimental os animais receberam água, sal mineralizado, silagem de milho (Zea mays) e feno de coast cross (Cynodon dactlon L.) "ad libitum", e ainda foram suplementados com ração composta por milho $(70 \%)$ e soja $(30 \%)$ na proporção de $500 \mathrm{~g}$ animal dia. Antes do início do experimento, os animais foram desverminados e submetidos a exames clínicos e laboratoriais.

Os animais foram distribuídos em dois grupos: grupo inoculado (G1) composto pelos animais $02,06,07,08,09 \mathrm{e}$ 10 e grupo testemunho (G2) composto pelos animais $01,03,04$ e 05 .

A cepa de T. evansi utilizada foi isolada por Moreira e Machado ${ }^{17}$ de um cão naturalmente infectado. Tripomastigotas sangüícolas deste parasita foram colhidos em solução de Alsever, adicionada de Dimetil sulfóxido (DMSO) a 10\% e criopreservada em nitrogênio a $-196^{\circ} \mathrm{C}$.

Os caprinos do grupo G1 foram inoculados via intravenosa com $1 \mathrm{~mL}$ do inóculo padronizado, de maneira que cada animal recebeu cerca de $2,38 \times 10^{6}$ tripomastigotas de T. evansi. Durante o experimento foi realizada prova biológica em ratos no $10^{\circ}, 40^{\circ}, 70^{\circ}, 100^{\circ}, 130^{\circ}, 160^{\circ}$, $190^{\circ}, 220^{\circ}, 250^{\circ}, 280^{\circ}, 310^{\circ}, 340^{\circ}, 365^{\circ}$ dias após a inoculação (DAI) e parasitemia por exame da gota espessa e método de concentração de Strout para a confirmação da presença do agente nos animais inoculados.

Alíquotas de sangue para obtenção de soro foram colhidas, por punção da veia jugular externa, imediatamente antes das inoculações, diariamente até $14^{\circ} \mathrm{DAI}$, semanalmente até $98^{\circ} \mathrm{DAI}$ e quinzenalmente até $364^{\circ} \mathrm{DAI}$.

A concentração plasmática de proteína total foi determinada pelo método de Biureto. Para o fracionamento das 
proteínas utilizou-se eletroforese em gel de poliacrilamida contendo dodecil sulfato de sódio (SDS-PAGE), conforme técnica descrita por Laemmli ${ }^{18}$. Após o fracionamento o gel foi corado durante 10 min. em solução de azul de coomassie e, em seguida, colocado em solução de ácido acético a 7\% para retirar o excesso de corante, até que as frações protéicas se apresentassem nítidas. As concentrações dessas proteínas foram determinadas em densitômetro computadorizado (Shimadzu CS 9301, Tokio, Japan). Como referência utilizou-se uma solução marcadora (Sigma, Saint Louis, USA) com pesos moleculares 36.000, 45.000, 66.000, 97.400, $116.000 \mathrm{e}$ 205.000 daltons (D), além de proteínas purificadas haptoglobina, a1-antitripsina.

Para a análise estatística empregou-se o delineamento inteiramente casualizado e as análises foram realizadas dentro de cada dia de observação, utilizando-se o teste de $\mathrm{t}$ para comparações múltiplas.

\section{Resultados e Discussão}

A primeira detecção do tripomastigota sangüícola nas cabras infectadas ocorreu no $21^{\circ} \mathrm{DAI}$, observado em exame de gota espessa. Posteriormente, os animais foram apresentando-se positivos, sendo o último no $35^{\circ}$ DAI. A partir do $95^{\circ} \mathrm{DAI}$, a parasitemia tornou-se negativa em diferentes momentos. Entretanto, a presença do parasita foi evidenciada no decorrer de todo o experimento através da prova biológica. Cabe ressaltar que nenhuma cabra inoculada apresentou hipertermia durante o período de avaliação.

O método de fracionamento de proteínas por eletroforese permitiu identificar 21 proteínas com pesos moleculares que variaram entre 16 e $165 \mathrm{kDa}$. Destas, 6 foram identificadas nominalmente (Tabela 1), sendo a transferrina, a albumina, a antitripsina, a haptoglobina, a glicoproteína ácida e a $\operatorname{IgG}$ de cadeia leve. As demais foram obtidas através de seus pesos moleculares. Considerando que o objeto de estudo deste trabalho foi avaliar o comportamento das proteínas de fase aguda, serão então discutidas as proteínas nominalmente identificadas neste experimento.

De acordo com a tabela 1 , os teores séricos da transferrina no $14^{\circ}, 42^{\circ}, 70^{\circ}, 98^{\circ}$, $210^{\circ}, 266^{\circ}$ e $364^{\circ}$ DAI (dias após a inoculação) apresentaram-se estatisticamente diferentes, sendo superiores nos animais inoculados (G1). Embora o tempo de meiavida desta proteína seja de oito a dez dias ${ }^{19}$, no presente trabalho esses valores permaneceram elevados nos animais inoculados até o final do período observado. Elevações nos teores séricos da albumina também foram observadas no $98^{\circ} \mathrm{DAI}$ nos animais do G1. Passos ${ }^{16}$ trabalhou com ovinos experimentalmente infectados com T. evansi e encontrou elevações no traçado da albumina durante os 240 dias de observação. Em ratos inoculados com a mesma cepa deste hematozoário, Teixeira ${ }^{6}$ observou aumento significativo da transferrina no $10^{\circ}$ DAI e reduções significativas nos teores séricos da albumina no $15^{\circ}$ e $60^{\circ}$ DAI. Entretanto, redução dos teores séricos da albumina em infecções com T. evansi foram observados em bezerros por Verman e Gautam ${ }^{13}$, em eqüinos por Brem, Monzon e Mancebo ${ }^{14}$, em hamsters por Monzón e Villavicencio ${ }^{20}$ e em cães por Sandoval et al. ${ }^{15}$.

Embora a albumina e a transferrina sejam consideradas de fase aguda negativa, tendendo a decrescer seus valores frente a condições inflamatórias ${ }^{8}$, ressalta-se que no presente experimento a presença do parasita foi confirmada durante todo período avaliado, tornando-se um fator causador de reação imunológica pelo organismo animal e, portanto, podendo ser a possível causa da elevação dos teores das mesmas.

Segundo Godson et al. ${ }^{21}$ as proteínas de fase aguda positiva se elevam imediatamente após a instalação de um processo inflamatório ou endotoxêmico. No presente estudo, observou-se que os valores séricos da antitripsina, haptoglobina, glicoproteína ácida e da $\operatorname{IgG}$ de cadeia leve não demonstraram alterações significativas. 
Tabela 1 - Médias (M), desvio-padrão (DP) e significância do teste t das concentrações séricas das frações protéicas identificadas nominalmente presentes no traçado eletroforético em gel de acrilamida (SDS-PAGE), de caprinos inoculados com T. evansi (G1) e nos do grupo testemunho (G2). Jaboticabal, 2006

\begin{tabular}{|c|c|c|c|c|c|c|c|c|c|c|c|c|c|c|}
\hline \multirow{2}{*}{$\begin{array}{l}\text { Proteína } \\
\text { PM (KD) }\end{array}$} & \multirow{2}{*}{$\mathbf{G}$} & \multicolumn{13}{|c|}{ Dias após a Inoculação com $T$. evansi } \\
\hline & & & 0 & 7 & 14 & 28 & 42 & 70 & 98 & 154 & 210 & 266 & 322 & 364 \\
\hline \multirow{5}{*}{$\begin{array}{l}\text { Proteína total } \\
\text { (g/dL) }\end{array}$} & \multirow{2}{*}{ G1 } & $\mathbf{M}$ & 0,91 & 0,86 & 0,89 & 0,89 & 0,93 & 0,90 & 0,91 & 0,91 & 0,92 & 0,95 & 0,93 & 0,94 \\
\hline & & DP & 0,04 & 0,02 & 0,04 & 0,03 & 0,02 & 0,03 & 0,03 & 0,03 & 0,03 & 0,03 & 0,03 & 0,04 \\
\hline & \multirow[b]{2}{*}{ G2 } & $\mathbf{M}$ & 0,91 & 0,87 & 0,87 & 0,87 & 0,88 & 0,86 & 0,87 & 0,87 & 0,88 & 0,92 & 0,93 & 0,90 \\
\hline & & DP & 0,04 & 0,03 & 0,06 & 0,04 & 0,04 & 0,03 & 0,01 & 0,02 & 0,03 & 0,02 & 0,01 & 0,03 \\
\hline & \multicolumn{2}{|c|}{ Teste $\mathbf{T}$} & $0,3675^{\mathrm{ns}}$ & $0,3899^{\mathrm{gns}}$ & $0,5115^{\mathrm{ns}}$ & $0,5134^{\mathrm{ns}}$ & $0,0330^{\mathrm{ns}}$ & $0,0673^{\text {ns }}$ & $0,0379^{\circ}$ & $0,0640^{\mathrm{ns}}$ & $0,1014^{\mathrm{ns}}$ & $0,1031^{\mathrm{ns}}$ & $0,9178^{\mathrm{ns}}$ & $0,5473^{\text {ns }}$ \\
\hline \multirow{5}{*}{$\begin{array}{c}\text { Transferrina } \\
75\end{array}$} & \multirow{2}{*}{ G1 } & M & 2,63 & 2,65 & 2,71 & 2,67 & 2,71 & 2,75 & 2,80 & 2,61 & 2,70 & 3,71 & 2,70 & 2,74 \\
\hline & & $\mathbf{D P}$ & 0,05 & 0,04 & 0,03 & 0,04 & 0,13 & 0,06 & 0,04 & 0,09 & 0,04 & 0,03 & 0,06 & 0,02 \\
\hline & \multirow{2}{*}{ G2 } & $\mathbf{M}$ & 2,62 & 2,62 & 2,62 & 2,63 & 2,54 & 2,64 & 2,66 & 2,56 & 2,62 & 2,63 & 2,69 & 2,59 \\
\hline & & $\mathbf{D P}$ & 0,03 & 0,03 & 0,07 & 0,16 & 0,05 & 0,06 & 0,03 & 0,07 & 0,06 & 0,03 & 0,04 & 0,04 \\
\hline & \multicolumn{2}{|c|}{ Teste $\mathbf{T}$} & $0,6897^{\mathrm{as}}$ & $0,1831^{\mathrm{ns}}$ & $0,0182^{*}$ & $0,4937^{\mathrm{ns}}$ & $0,0338^{*}$ & $0,0250^{*}$ & $0,0003^{* *}$ & $0,3765^{\mathrm{ns}}$ & $0,0281^{*}$ & $0,0003^{* *}$ & $0,6673^{\text {ns }}$ & $0,0001^{* *}$ \\
\hline \multirow{5}{*}{ Albumina } & \multirow{2}{*}{ G1 } & M & 3.59 & 3,53 & 3,53 & 3,53 & 3,55 & 3,57 & 3,59 & 3,61 & 3,61 & 3,71 & 3,63 & 3,69 \\
\hline & & DP & 0,04 & 0,02 & 0,04 & 0,03 & 0,05 & 0,02 & 0,02 & 0,04 & 0,03 & 0,03 & 0,06 & 0,03 \\
\hline & \multirow[b]{2}{*}{ G2 } & $\mathbf{M}$ & 3,57 & 3,53 & 3,49 & 3,54 & 3,54 & 3,54 & 3,55 & 3,61 & 3,58 & 3,68 & 3,65 & 3,66 \\
\hline & & $\mathbf{D P}$ & 0,02 & 0,04 & 0,10 & 0,03 & 0,05 & 0,04 & 0,01 & 0,05 & 0,02 & 0,01 & 0,02 & 0,01 \\
\hline & \multicolumn{2}{|c|}{ Teste $\mathbf{T}$} & $0,4591^{n s}$ & $0,9881^{\mathrm{ns}}$ & $0,3882^{\mathrm{ns}}$ & $0,6065^{\text {ns }}$ & $0,6381^{\text {ns }}$ & $0,1160^{\mathrm{ns}}$ & $0,0360^{*}$ & $0,8318^{\text {ns }}$ & $0,0644^{\mathrm{ns}}$ & $0,0903^{n s}$ & $0,4271^{n s}$ & $0,0768^{n}$ \\
\hline \multirow{5}{*}{$\begin{array}{c}\text { Antitripsina } \\
60\end{array}$} & \multirow{2}{*}{ Gl } & M & 3,11 & 3,07 & 3,14 & 3,14 & 3,19 & 3,15 & 3,13 & 2,96 & 3,02 & 3,01 & 3,06 & 2,99 \\
\hline & & DP & 0,06 & 0,06 & 0,11 & 0,07 & 0,11 & 0,08 & 0,09 & 0,12 & 0,14 & 0,07 & 0,09 & 0,08 \\
\hline & \multirow{2}{*}{ G2 } & $\mathbf{M}$ & 3,15 & 3,12 & 3,15 & 3,15 & 3,15 & 3,11 & 3,11 & 2,92 & 3,05 & 3,00 & 2,99 & 3,01 \\
\hline & & $\mathbf{D P}$ & 0,07 & 0,07 & 0,11 & 0,10 & 0,07 & 0,08 & 0,03 & 0,13 & 0,11 & 0,07 & 0,08 & 0,09 \\
\hline & \multicolumn{2}{|c|}{ Teste $\mathbf{T}$} & $0,3774^{\mathrm{ss}}$ & $0,2929^{\mathrm{gs}}$ & $0,9174^{\mathrm{ns}}$ & $0,9197^{n s}$ & $0,4687^{\mathrm{as}}$ & $0,4184^{\mathrm{ns}}$ & $0,6535^{\mathrm{ns}}$ & $0,6376^{\mathrm{ns}}$ & $0,7103^{\text {ns }}$ & $0,8092^{\mathrm{ns}}$ & $0,1647^{n s}$ & $0,7030^{\text {ns }}$ \\
\hline \multirow{5}{*}{$\begin{array}{c}\text { Haptoglobina } \\
44\end{array}$} & \multirow{2}{*}{ Gl } & $\mathbf{M}$ & 0,84 & 0,69 & 0,92 & 0,84 & 0,67 & 0,53 & 0,54 & 0,58 & 0,35 & 0,00 & 0,22 & 0,14 \\
\hline & & DP & 0,16 & 0,35 & 0,18 & 0,07 & 0,39 & 0,42 & 0,42 & 0,45 & 0,63 & 0,00 & 0,53 & 0,32 \\
\hline & \multirow[b]{2}{*}{ G2 } & $\mathbf{M}$ & 0,87 & 0,75 & 0,62 & 0,42 & 0,58 & 0,56 & 0,05 & 0,46 & 0,00 & 0,00 & 0,00 & 0,00 \\
\hline & & $\mathbf{D P}$ & 0,07 & 0,13 & 0,42 & 0,49 & 0,41 & 0,43 & 0,11 & 0,53 & 0,00 & 0,00 & 0,00 & 0,00 \\
\hline & \multicolumn{2}{|c|}{ Teste $\mathbf{T}$} & $0,7883^{\mathrm{ns}}$ & $0,7236^{\mathrm{ms}}$ & $0,1536^{\mathrm{ns}}$ & $0,0720^{\mathrm{ms}}$ & $0,7225^{\mathrm{ns}}$ & $0,8953^{\mathrm{ns}}$ & $0,0577^{n s}$ & $0,7187^{\mathrm{ns}}$ & $0,3121^{\mathrm{ns}}$ & 0,0000 & $0,4468^{\mathrm{ns}}$ & $0,4071^{\text {ns }}$ \\
\hline & & $\mathbf{M}$ & 1,50 & 1,29 & 0,74 & 0,69 & 0,71 & 0,13 & 0,37 & 0,53 & 1,22 & 0,79 & 1,10 & 0,69 \\
\hline Glicoproteína & G1 & DP & 0,39 & 0,36 & 0,68 & 0,67 & 0,62 & 0,33 & 0,63 & 0,42 & 0,36 & 0,40 & 0,58 & 0,67 \\
\hline & & $\mathbf{M}$ & 1,34 & 0,80 & 1,00 & 0,55 & 0,56 & 0,00 & 0,00 & 0,38 & 1,07 & 0,75 & 1,25 & 0,88 \\
\hline 38 & & DP & 0,15 & 0,54 & 0,06 & 0,69 & 0,47 & 0,00 & 0,00 & 0,44 & 0,38 & 0,50 & 0,07 & 0,14 \\
\hline & & te $T$ & $0,4541^{n s}$ & $0,1235^{\mathrm{ns}}$ & $0,4630^{\mathrm{ns}}$ & $0,7600^{\mathrm{ns}}$ & $0,6985^{\mathrm{ns}}$ & $0,4468^{\mathrm{ns}}$ & $0,2778^{=5}$ & $0,5993^{\mathrm{ns}}$ & $0,5657^{\mathrm{ns}}$ & $0,8801^{\mathrm{ns}}$ & $0,6269^{\mathrm{ns}}$ & $0,5995^{\mathrm{ns}}$ \\
\hline & G1 & $\mathbf{M}$ & 2,45 & 2,44 & 2,48 & 2,46 & 2,47 & 2,50 & 2,43 & 2,55 & 2,41 & 2,37 & 2,17 & 2,36 \\
\hline & & DP & 0,06 & 0,04 & 0,10 & 0,04 & 0,04 & 0,09 & 0,07 & 0,06 & 0,06 & 0,06 & 0,10 & 0,07 \\
\hline $\lg$ & & $\mathbf{M}$ & 2,54 & 1,82 & 2,47 & 2,51 & 2,49 & 2,46 & 2,39 & 2,56 & 2,36 & 2,36 & 2,36 & 2,29 \\
\hline 26 & & DP & 0,10 & 0,22 & 0,06 & 0,06 & 0,09 & 0,71 & 0,05 & 0,07 & 0,08 & 0,08 & 0,34 & 0,12 \\
\hline & & te $\mathbf{T}$ & $0,1098^{n s}$ & $0,2341^{1 \mathrm{ss}}$ & $0,8488^{\mathrm{as}}$ & $0,1219^{\mathrm{ns}}$ & $0,6379^{\mathrm{ns}}$ & $0,5075^{\mathrm{as}}$ & $0,3071^{\mathrm{ss}}$ & $0,7749^{\mathrm{as}}$ & $0,3073^{\mathrm{ns}}$ & $0,8355^{\mathrm{ns}}$ & $0,2338^{\mathrm{ns}}$ & $0,3318^{\mathrm{ns}}$ \\
\hline
\end{tabular}

Dados transformados para $\log (\mathrm{x}+1)$; G - grupo; PM - peso molecular

Estes resultados diferiram de Teixeira ${ }^{6}$ que observou em ratos inoculados com T. evansi, redução da antitripsina no $5^{\circ} \mathrm{DAI}$ e aumento no $45^{\circ}$ DAI, bem como da glicoproteína ácida e da haptoglobina. Entretanto, é importante aventar que no presente experimento, embora não tenha apresentado variações significativas, a glicoproteína ácida oscilou de sobremaneira, apresentando valores que variaram de 0,13 a $1,50 \mathrm{mg} /$ $\mathrm{dL}$, sofrendo reduções e elevações que podem ter relação com a permanência do tripanossoma.

Merece destaque a observação de que no presente trabalho, as proteínas de fase aguda identificadas permaneceram presentes ao longo do experimento, alertando para a importância de que mesmo que não tenham apresentado diferenças significativas, ainda assim, apresentaram variações em seus valores, fato que ressalta a necessidade de novos estudos.

Os teores séricos da proteína total neste trabalho não apresentaram variações significativas, exceto no $98^{\circ} \mathrm{DAI}$, no qual foram mais elevadas nos animais inoculados. Em bovinos infectados com T. evansi, Verman e Gautam ${ }^{22}$ também não observaram diferenças significativas na proteína total em 40 dias de observação. Resultado semelhante foi obtido por Marques $^{23}$ em eqüinos infectados com este 
hematozoário.

No presente trabalho, ressalta-se que os animais inoculados não apresentaram sintomas clínicos desta tripanossomíase, embora todas as provas biológicas e parasitêmicas tenham sido positivas, fato que sustenta a possibilidade desta espécie comportar-se como reservatório da doença.

\section{Electrophoresis profile of the acute phase proteins of goats experimentally infected with Trypanosoma evansi.}

\section{Abstract}

Considered as one of the main agents of the tripanossomiases, Trypanosoma evansi causes a disease generically know as "surra", with wide geographic occurence. This work has the aim to study the electrophoretic profile of the acute phase proteins of goats, experimentally infected with T. evansi. Ten crossbread female goats, around 4 months of age, clinically healthy and serum negative for the presence of antibodies anti-T. evansi (IFAT) were used. The animals were divided in two groups: six were inoculated (G1) intravenously with $2,38 \times 10^{6}$ tripomastigotes of T. evansi and four were kept as noninfected controls. The blood for serum was collected daily until the 14 days after inoculation (DAI), weekly up to the $98^{\text {th }}$ DAI and every two weeks up to the $364^{\text {th }}$ DAI. The serum proteins were separacted by sodium dodecyl sulphate-polyacrylamide gel electrophoresis (SDSPAGE). Twenty-one proteins were found in the serum of the goats, eight were nominally identified; phosphorylase, transferrin, albumin, antitrypsin, acid glicoprotein, haptoglobin, hemoglobin, and light chain immunoglobulin.

\section{Referências}

1 WOO, P. T. K. Salivarian trypanosomes producing disease in livestock outside of sub-Saharan Africa. In: KREIER, J. P. Parasitic protozoa. New York: Academic Press, 1977. v. 1, p. 270-295.

2 TOURATIER, L. Dixième reunion internationale sur Trypanosoma evansi: rapport du groupe de travail. Rev. Sci. Tech. Off. Int. Epiz., v. 9, n. 4, p. 1197-1207, 1990.

3 GUTIEEREZ, C.; CORBERA, J. A.; MORALES, M.; BÜSCHER, P. Trypanosomosis in goats: current status. Ann. N. Y. Acad. Sci., v. 1081, p. 300-310, 2006.

4 NGERANWA, J. J.; GATUMBI, P. K.; MUTIGA, E. R.; AGUMBAH, G. J. O. Pathogenesis of Trypanosoma (brucei) evansi in small East African goats. Res. Vet. Sci., v. 54, p. 283-289, 1993.

5 SHARMA, D. K.; CHAUHAN, P. P. S.; SAXENA, V. K.; AGRAWAL, R. D. Haematological changes in experimental trypanosomiasis in Barbari goats. Small Ruminant Research, v. 38, n. 2, p. 145-149, 2000.

6 TEIXEIRA, M. C. A. Proteinogramas séricos de ratos wistar experimentalmente infectados com Trypanosoma evansi Steel, 1885 (Sarcomastigophora: Trypanosomatidae). 2006. 80 f. Dissertação (Mestrado em Clínica Médica Veterinária) - Faculdade de Ciências Agrárias e Veterinárias, Universidade Estadual Paulista, Jaboticabal, 2006.

7 GRURYS, E.; OBWOLO, M. J.; TOUSSAINT, M. J. $M$. Diagnostic significance of the major acute phase proteins in veterinary clinical chemistry: a review. Vet. Bull., v. 64, n. 11, p. 1009-1018, 1994

$8 \mathrm{SINGH}$, S. V.; PACHAURI, S. P. Acute phase proteins in bovine mastitis. Indian J. Anim. Sci., v. 72, n. 1, p. 20-22, 2002.

9 KANEKO, J. J.; HARVEY, J. W.; BRUSS, M. L. Clinical biochemistry of domestic animals. $6^{\text {th }}$ ed. San Diego: Academic Press, 1997. 932 p.

10 HORADAGODA, N. U.; KNOX, K. M.; GIBBS, H. A.; REID, S. W.; HORADAGODA, A.; EDWARDS, S. E.; ECKERSALL, P. D. Acute phase proteins in cattle: discrimination between acute and chronic inflammation. Vet. Rec., London, v.144, n.16, p.437442, 1999.

11 SKINNER, J. G.; ROBERTS, L. Haptoglobin as an indicator of infection in sheep. Vet. Rec., v. 134, n. 2, p. 33-36, 1994.

12 BOID, R.; LUCKINS, A. G.; RAE, P. F.; GRAY, A. R.; MAHMOUD, M. M.; MALIK, K. H. Serum immunoglobulin levels and electrophoretic patterns of 
serum proteins in camels infected with Tripanosoma evansi. Vet. Parasitol., v. 6, n. 4, p. 333-345, 1980.

13 VERMAN, B. B.; GAUTAM, O. P. Electrophoretic analysis of serum proteins of calves experimentaly infected with Trypanosoma evansi. Indian J. Anim. Health, v.18, p. 33-37, 1979.

14 BREM, J. J.; MONZÓN, C. M.; MANCEBO, O. A. Cambios hematologicos en la tripanosomiasis equina experimental (T. equinum, Vogés 1901). Rev. Mil. Vet., v. 32, n. 150, p. 413-420, 1984.

15 SANDOVAL G. L.; COPPO, N. B.; SANCHEZ NEGRETTE, M.; COPPO, J. A. Alterações bioquímicas e histopatológicas de um cão e ratos infectados com Trypanosoma evansi. Hora Vet., v. 14, n. 81, p. 53-55, 1994.

16 PASSOS, P. B. Infeccção experimental em ovinos com Trypanosoma evansi Steel, 1885 (Sarcomastigophora: Trypanosomatidae). 2004. 236 f. Tese (Doutorado) - Faculdade de Ciências Agrárias e Veterinárias, Universidade Estadual Paulista, Jaboticabal, 2004.

17 MOREIRA, R. D.; MACHADO, R. Z. Identificação e isolamento do Trypanosoma equinum em um cão do Município de Camapuã, M.S. In: ENCONTRO DE PESQUISAS VETERINÁRIAS, 10., 1985, Jaboticabal. Resumos... Jaboticabal: Faculdade de Ciências Agrárias e Veterinárias, 1985. p. 66.
18 LAEMMLI, U. K. Cleavage of structural proteins during the assembly of the head of bacteriophage $T_{4}$. Nature, v. 227, p. 680-685, 1970.

19 JAIN, N. C. Essentials of veterinary hematology. Philadelphia: Lea \& Febiger, 1993. 417 p.

20 MONZÓN C. M.; VILLAVIVENCIO, V. I. Serum proteins in guinea-pigs and horse infected with Trypanosoma evansi (Steel, 1885). Vet. Parasitol., v. 36 n. 3-4, p. 295-301, 1990.

21 GODSON D. L.; CAMPOS, M.; ATTAH-POKU, S. K.; REDMOND, M. J.; CORDEIRO, D. M.; SETHI, M. S.; HARLAND, R. J.; BABIUK, L. A. Serum haptoglobin as an indicator of the acute phase response in bovine respiratory disease. Vet. Immunol. And Immunopathol., v. 51 , p. 277-292, 1996.

22 Verman, B. B.; GAUTAM, O. P. Serological diagnosis of experimantal bovine surra (Trypanosoma evansi infection) - A comparisionof passive haemagglutination, gel diffusion and indirect fluorescent antibody test. Indian Vet. J., v. 54, p. 809813, 1982.

23 MARQUES, L. C. Infecção experimental em equinos com Trypanosoma evansi (Steel, 1885) (Sarcomastigophora: Trypanomatidae). 1996. 134 f. Tese (Livre Docência em Clínica Médica) - Faculdade de Ciências Agrárias e Veterinárias, Universidade Estadual Paulista, Jaboticabal, 1996. 